\title{
An Exploratory Study of the Relative Effects of Various Protective Factors on Depressive Symptoms Among Older People
}

\author{
Caitlin Worrall ${ }^{1 *}$, Michelle I. Jongenelis ${ }^{2}$, Peter M. McEvoy ${ }^{1,3}$, Ben Jackson ${ }^{4}$, \\ Robert U. Newton ${ }^{5}$ and Simone Pettigrew ${ }^{6}$ \\ ${ }^{1}$ School of Psychology, Curtin University, Bentley, WA, Australia, ${ }^{2}$ Melbourne Centre for Behaviour Change, Melbourne \\ School of Psychological Sciences, The University of Melbourne, Melbourne, VIC, Australia, ${ }^{3}$ Centre for Clinical Interventions, \\ Perth, WA, Australia, ${ }^{4}$ School of Human Sciences (Exercise and Sports Science), University of Western Australia, Crawley, \\ WA, Australia, ${ }^{5}$ Exercise Medicine Research Institute, Edith Cowan University, Joondalup, WA, Australia, ${ }^{6}$ The George \\ Institute for Global Health: Australia, Newtown, NSW, Australia
}

\section{OPEN ACCESS}

Edited by:

Shane Andrew Thomas, Australian National University, Australia

Reviewed by: Edimansyah Abdin, Institute of Mental Health, Singapore Mythily Subramaniam, Institute of Mental Health, Singapore

*Correspondence:

Caitlin Worrall caitlin.worrall@postgrad.curtin.edu.au

Specialty section: This article was submitted to Aging and Public Health,

a section of the journal

Frontiers in Public Health

Received: 02 July 2020 Accepted: 07 October 2020 Published: 12 November 2020

Citation:

Worrall C, Jongenelis MI, McEvoy PM, Jackson B, Newton $R U$ and Pettigrew S (2020) An Exploratory Study of the Relative Effects of Various

Protective Factors on Depressive Symptoms Among Older People.

Front. Public Health 8:579304. doi: 10.3389/fpubh.2020.579304
Objective: The present study investigated the relative importance of various factors found to be negatively associated with depressive symptoms in older adults and assessed the potential moderating effect of sociodemographic characteristics for each factor.

Method: Depressive symptoms were measured with the Center of Epidemiological Studies Depression Scale. Psychological, social, and physical health measures relating to the following factors were also administered: personal growth, purpose in life, self-esteem, self-efficacy, social support, self-rated health, life satisfaction, and physical activity. Multivariate linear regression analysis was used to investigate the most important factors associated with depressive symptoms, and moderation analyses were employed to identify any moderating effects of sociodemographic factors.

Results: Life satisfaction, self-esteem, and purpose in life were found to be negatively associated with depressive symptoms. Only one moderating effect was observed-the negative relationship between life satisfaction and depressive symptoms was significantly stronger among the younger respondents.

Conclusion: These findings suggest that strategies for the prevention or amelioration of depressive symptoms across subgroups of the senior population could be optimized by focusing on enhancing life satisfaction, self-esteem, and purpose in life.

Keywords: older adults, aging-old age-seniors, protective factors, comprehensive model, depressive symptoms

\section{INTRODUCTION}

Depression is a leading cause of burden of disease worldwide (1). With the proportion of people aged $60+$ years worldwide projected to increase from $13 \%$ in 2017 to $21 \%$ in 2050 (2), the prevention and amelioration of depressive symptoms among older adults is recognized as a public health priority to ensure increasing life expectancy is accompanied by positive psychological well-being (3). Depressive symptoms can be especially debilitating for older adults because they (i) are particularly intransigent among members of this population 
segment (4); (ii) complicate the treatment of chronic diseases (5), which are disproportionately prevalent among older adults (6); and (iii) often go undetected due to uncertainty about what constitutes depressive symptoms in this cohort $(7,8)$. In addition, older adults tend to have more limited social networks and suboptimal coping strategies compared to younger cohorts, which can make them more vulnerable to depressive symptoms (9-11). The development of effective strategies to prevent and ameliorate depressive symptoms is critical to optimize older people's well-being and reduce health system costs $(5,12)$.

Identifying factors that can protect against later life depressive symptoms is important for informing the development of appropriate prevention and amelioration strategies. Previous research suggests that relevant modifiable factors that could be the focus of such strategies include social support, self-rated health, and physical activity (13-16). There is strong evidence for the protective effects of each of these factors, individually and in various combinations, across both cross-sectional and longitudinal studies (17-26). Overall, research investigating the trajectory of depressive symptoms in older people has found higher levels of social support, self-rated health, and physical activity to be associated with (i) fewer depressive symptoms at baseline and (ii) a lower likelihood of depressive symptoms emerging over time $(24,25)$. In addition to these well-established protective factors, there is growing evidence that life satisfaction, purpose in life, personal growth, self-efficacy, and self-esteem are protective against depressive symptoms (15, 26-34).

While previous work supports the importance of each of these protective factors, to date there does not appear to be research incorporating them all to provide an understanding of their relative effects to enable appropriate prioritization in intervention design. To address this deficit, the present study adopted an exploratory approach to investigate the relative importance of modifiable factors that have been found to be protective against depressive symptoms (as outlined above). A second aim was to investigate whether sociodemographic characteristics (gender, age, living arrangement, and educational attainment) moderate the relationships between these protective factors and depressive symptoms to assist in identifying specific sub-segments of older adults who are likely to benefit most from interventions. The results provide insights into which factors are likely to be important to consider in the development of population-level depressive symptom prevention and amelioration strategies for older people, and also suggest key variables to incorporate in future longitudinal research designed to further extend this field of research.

\section{METHOD}

\section{Design, Recruitment, and Procedure}

The data used in this cross-sectional study were collected between 2014 and 2016 as part of a larger project exploring healthy aging among older adults (35). Ethical approval was received from Curtin University's Human Research Ethics Committee. Eligibility criteria were being aged 60 years or older, living in a community setting, and being fully retired. Participants were recruited via a range of methods including notices in community
TABLE 1 | Sample characteristics.

\begin{tabular}{|c|c|c|c|}
\hline Characteristics (\%) & $\begin{array}{c}\text { Sample } \\
(N=801)\end{array}$ & $\begin{array}{c}\text { Australian } 60+ \\
\text { population }^{a} \\
(N=4,976,160)\end{array}$ & $P$ \\
\hline Gender & & & 0.317 \\
\hline Female & 61 & 53 & \\
\hline Male & 39 & 47 & \\
\hline Age & & & 0.085 \\
\hline $60-69$ & 41 & 50 & \\
\hline $70-79$ & 46 & 31 & \\
\hline $80+$ & 13 & 19 & \\
\hline Education & & & 0.120 \\
\hline Non-tertiary & 43 & 55 & \\
\hline Tertiary & 57 & 45 & \\
\hline Living arrangement & & & 0.040 \\
\hline Not living alone & 65 & 79 & \\
\hline Living alone & 35 & 21 & \\
\hline
\end{tabular}

Education $=$ highest level of education attained.

a Percentages based on data for all women and men aged 60 years and older from the 2016 Australian Census (36).

newspapers, radio announcements, and flyers placed at seniors' events and retirement villages across the metropolitan area of Perth, Western Australia.

In total, 801 adults met the above eligibility criteria and provided written informed consent. Participation involved completing a self-administered survey that included psychological, social, and physical health measures validated for use in older adults. These measures are described in detail below. Unless otherwise stated, the items forming each of the scales included in the survey were summed for analysis purposes.

\section{Sample Characteristics}

The final sample consisted of older adults ranging in age from 60 to 95 years $(\mathrm{M}=71.93$ years, $\mathrm{SD}=6.68), 61 \%$ of whom were female. Characteristics of the present sample alongside those of the Australian older adult population are presented in Table 1. Pearson chi-square tests indicated the sample was representative in terms of gender, age, and education but not living arrangement: the present sample had a significantly higher proportion of older adults living alone compared to the Australian older adult population.

\section{Outcome Variable}

Depressive symptoms were assessed using the 20-item Center for Epidemiological Studies Depression Scale [CES-D: (37)]. Participants responded to each item (e.g., "I felt that everything I did was an effort") on a 4-point scale that ranged from 0 (rarely or none of the time) to 3 (most or all of the time). Cronbach's alpha in the present study was 0.87 , indicating good reliability.

\section{Independent Variables}

The 14-item Personal Growth and Purpose in Life subscales of Ryff's (38) Psychological Well-Being Scale were used to measure personal growth and purpose in life, respectively. Responses to 
items (e.g." "I have the sense that I have developed a lot as a person over time"; "I have a sense of direction and purpose in life") were made on a scale of 1 (strongly disagree) to 5 (strongly agree). Cronbach's alpha in the present study indicated good reliability for scores on both the Personal Growth $(\alpha=0.86)$ and Purpose in Life $(\alpha=0.88)$ subscales.

Self-esteem was measured using the 10-item Rosenberg SelfEsteem Scale (39). Respondents answered each item (e.g., "I feel that I'm a person of worth, at least on an equal plane with others") on a 4-point scale that ranged from 0 (strongly disagree) to 3 (strongly agree). Cronbach's alpha for scores on this scale was 0.88 , indicating good reliability. The 24-item Social Provision Scale (40) was used to assess social support. Each item (e.g., "There is someone I could talk to about important decisions in my life") was measured on a 4-point scale that ranged from 1 (strongly disagree) to 4 (strongly agree). The scores on this scale were found to have excellent reliability ( $\alpha=0.92$ ).

Self-efficacy was assessed using the 10-item General SelfEfficacy Scale (41). Participants responded to each item (e.g., "I can solve most problems if I invest the necessary effort") on a 4-point scale that ranged from 1 (not at all true) to 4 (exactly true). Cronbach's alpha was 0.90 , indicating excellent reliability. Life satisfaction was assessed by asking participants to rate how satisfied they are with their life on a scale of 1 (very satisfied) to 5 (very dissatisfied) [adapted from the World Values Survey: (42)]. For analysis purposes, this variable was reverse scored.

Level of physical activity was measured by asking participants: How many hours of moderate to vigorous activity (that is, physical activity that makes you breathe harder or puff and pant) would you do in an average week? The definition provided for moderate to vigorous activity was based on the Australian Department of Health's Physical Activity and Sedentary Behavior Guidelines (43). Response options were: $0 \mathrm{~h},<1 \mathrm{~h}$, between $1-2 \mathrm{~h}$, between 2-3 h, between 3-4h, between $4-5 \mathrm{~h}$, and 5 or more $\mathrm{h}$.

Consistent with previous research (44), self-rated health was assessed by asking participants to describe their physical health on a scale from 1 (very good) to 5 (very bad). For analysis purposes, this variable was reverse scored.

Sociodemographic variables included age (treated as continuous), gender $(1=$ male, $2=$ female; treated as dichotomous), living arrangement $(1=$ lives alone, $2=$ does not live alone; treated as dichotomous), and highest level of education attained (no formal school/primary school, high school, technical/trade certificate, undergraduate, postgraduate; treated as continuous).

\section{Statistical Analysis}

Descriptive statistics for each modifiable protective factor are presented in Table 2. Univariate linear regression analyses were conducted to assess the relationships between each of the independent variables and the outcome variable of depressive symptoms (treated as continuous). Independent variables found to be significantly associated with depressive symptoms were then simultaneously entered into a linear multivariate regression model using SPSS 26. The Variance Inflation Factor (VIF) was used to assess for multicollinearity.

Moderation analyses were conducted using the PROCESS macro in SPSS to determine if the sociodemographic variables
TABLE 2 | Descriptive statistics for tested protective factors (IVs) and depressive symptoms.

\begin{tabular}{|c|c|c|c|c|c|}
\hline IVs & $\begin{array}{c}\mathrm{M} \\
(\mathrm{SD})\end{array}$ & $\begin{array}{c}\text { Sample } \\
\text { range }\end{array}$ & $\begin{array}{l}\text { Scale } \\
\text { range }\end{array}$ & Skewness & Kurtosis \\
\hline Life satisfaction & $\begin{array}{c}4.07 \\
(0.82)\end{array}$ & $1-5$ & $1-5$ & -0.99 & 1.19 \\
\hline Self-esteem & $\begin{array}{l}23.48 \\
(4.96)\end{array}$ & $1-30$ & $0-30$ & -0.68 & 0.43 \\
\hline Purpose in life & $\begin{array}{c}66.57 \\
(11.72)\end{array}$ & $18-84$ & $14-84$ & -0.76 & 0.43 \\
\hline Social support & $\begin{array}{c}79.00 \\
(10.41)\end{array}$ & 33-96 & 24-96 & -0.58 & 0.49 \\
\hline Self-rated health & $\begin{array}{l}4.00 \\
(0.77)\end{array}$ & $1-5$ & $1-5$ & -0.99 & 1.20 \\
\hline Self-efficacy & $\begin{array}{l}32.19 \\
(4.38)\end{array}$ & $12-40$ & $10-40$ & -0.37 & 0.77 \\
\hline Physical activity & $\begin{array}{c}3.77 \\
(1.82)\end{array}$ & $1-7$ & $1-7$ & 0.39 & -0.94 \\
\hline Personal growth & $\begin{array}{c}69.48 \\
(10.06)\end{array}$ & 29-84 & $14-84$ & -0.73 & 0.27 \\
\hline $\begin{array}{l}\text { Depressive } \\
\text { symptoms }\end{array}$ & $\begin{array}{c}9.02 \\
(8.14)\end{array}$ & $0-54$ & $0-60$ & 1.68 & 3.59 \\
\hline
\end{tabular}

IVs = independent variables; $M=$ mean; $S D=$ standard deviation.

TABLE 3 | Unstandardized parameter estimates, standardized parameter estimates, and standard errors for the multivariate model (in descending order of part $\left.r^{2}\right)$.

\begin{tabular}{|c|c|c|c|c|c|c|}
\hline IVs & B & $S E$ & $\beta$ & $p$ & $95 \% \mathrm{Cl}$ for $\mathrm{B}$ & Part $r^{2}$ \\
\hline Life satisfaction & -2.76 & 0.33 & -0.28 & $<0.001$ & $-3.40,-2.12$ & -0.21 \\
\hline Self-esteem & -0.42 & 0.06 & -0.26 & $<0.001$ & $-0.54,-0.30$ & -0.17 \\
\hline Purpose in life & -0.13 & 0.03 & -0.19 & $<0.001$ & $-0.19,-0.07$ & -0.11 \\
\hline Social support & -0.07 & 0.03 & -0.08 & 0.012 & $-0.12,-0.02$ & -0.06 \\
\hline Self-rated health & -0.77 & 0.30 & -0.07 & 0.011 & $-1.37,-0.18$ & -0.06 \\
\hline Self-efficacy & -0.13 & 0.06 & -0.07 & 0.018 & $-0.25,-0.02$ & -0.06 \\
\hline Living alone & -0.82 & 0.45 & -0.05 & 0.066 & $-1.70,0.06$ & -0.05 \\
\hline Physical activity & 0.11 & 0.12 & 0.03 & 0.338 & $-0.12,0.35$ & 0.02 \\
\hline Personal growth & 0.01 & 0.03 & 0.01 & 0.758 & $-0.05,0.06$ & 0.01 \\
\hline Education & -0.00 & 0.19 & 0.00 & 0.997 & $-0.38,0.38$ & 0.00 \\
\hline
\end{tabular}

IVs = independent variables; $B=$ unstandardized estimates; $S E=$ standard error of $B$; $\beta=$ standardized estimate; $p=$ significance value; $\mathrm{Cl}=$ confidence interval; Part $r^{2}=$ proportion of unique variance accounted for. Results significant at $p<0.005$ are presented in bold.

of gender, age, level of education, or living alone moderated the relationship between each of the significant independent variables and the outcome variable of depressive symptoms (45). Each of the independent variables found to be significant in univariate analyses and each of the sociodemographic variables were entered in analyses separately. Bootstrapping was performed ( $n=5,000$ samples), and a Bonferroni-adjusted alpha level of $<0.005$ was used to control for the family-wise error rate. Missing data were treated listwise.

\section{RESULTS}

\section{Regression Analyses}

Univariate regression analyses showed that life satisfaction, purpose in life, personal growth, self-esteem, social support, 
TABLE 4 | Significant moderating effect of age between life satisfaction and depressive symptoms.

\begin{tabular}{lcccc}
\hline Age & B & SE & $\boldsymbol{p}$ & $\mathbf{9 5 \%}$ Cl for B \\
\hline 65.25 (-1SD) & -6.82 & 0.35 & $<0.001$ & $-5.98,-4.35$ \\
71.78 (Mean) & -5.99 & 0.28 & $<0.001$ & $-6.54,-5.45$ \\
78.30 (+1SD) & -5.16 & 0.41 & $<0.001$ & $-5.98,-4.35$ \\
\hline
\end{tabular}

$B=$ unstandardized estimates; $S E=$ standard error of $B ; p=$ significance value; $C /$ for $B$ $=$ confidence interval. Bonferroni-adjusted alpha level of $<0.005$.

self-efficacy, physical activity, self-rated health, educational attainment, and living arrangement were all negatively associated with depressive symptoms (see Supplementary Table 1 for results of univariate regressions). A multivariate regression analysis combining these variables into a single model was used to explore the relative importance of these factors. VIF was $<10$ indicating that multicollinearity was not an issue. The model explained $55.6 \%$ of the variance in depressive symptoms $\left(F_{(10,734)}\right.$ $=91.93, p<0.001)$. The variables in the model that remained significantly and negatively associated with depressive symptoms at the Bonferroni-adjusted alpha level of $<0.005$ in descending order of effect were: life satisfaction, self-esteem, and purpose in life (see Table 3).

\section{Moderating Effects}

At the Bonferroni-adjusted alpha level of $<0.005$, a significant moderating effect of age was observed for life satisfaction (B $=0.13, \mathrm{SE}=0.04, p<0.002,95 \% \mathrm{CI}$ for $\mathrm{B}[0.05,0.21])$. See Supplementary Table 2 for results of moderation analyses. Post-hoc investigation of this effect showed that life satisfaction was negatively associated with depressive symptoms for all age groups, but the strength of the association was stronger for those participants below the average age of this sample compared to those of mean age or older (see Table 4 and Supplementary Figure 1 for significant results). Age did not moderate the relationships between any of the other independent variables and depressive symptoms, nor were there significant moderating effects observed for gender, living arrangement, or educational attainment (see Supplementary Table 2).

\section{DISCUSSION}

To better understand the nature of the relationships between factors that are particularly important in protecting against depressive symptoms among older adults, the present study combined a broad range of factors that have been identified in previous research as being potentially relevant. To assess whether interventions should be targeted at specific subgroups of the wider older adult population, a second aim of this study was to investigate whether sociodemographic characteristics moderated any of the relationships between each protective factor and depressive symptoms.

The tested model explained a large proportion (55.6\%) of the variance in depressive symptoms. Life satisfaction, self-esteem, and purpose in life were found to have the strongest (negative) association with depressive symptoms, which is consistent with previous longitudinal research $(26,30-33)$. However, this past work examined each of these variables in isolation or in models including a limited number of factors. The results of the present study indicate that even when considering a larger number of potential variables, life satisfaction, self-esteem, and purpose in life may be especially important in preventing and ameliorating depressive symptoms among older people.

The results of the present study in relation to physical activity are in contrast with the conclusions of a recent systematic review that found a negative relationship between extent of participation in physical activity and the experience of depressive symptoms among older people (16). The non-significant relationship found here may reflect the range of other psychological variables included in the study and their relative importance in protecting against depressive symptoms. Measurement limitations may also have played a role, such as the reliance on self-report $(46,47)$ and the assessment of only moderate to vigorous activity, which may not adequately capture all forms of protective activity relevant to older people $(18,21-23)$.

In terms of the moderation analyses used to assess whether interventions should target particular groups of older adults, just one moderating effect (age) was found, whereby a stronger relationship was found between life satisfaction and depressive symptoms among those participants below the average age of this sample, thus suggesting that interventions to improve life satisfaction could be particularly beneficial for those who are in this younger category (and likely to be newly retired). There is little prior work with which to compare these moderation outcomes. Some studies have examined the moderating effects of age, gender, education level, and living arrangement on the relationship between social support and depressive symptoms (48-51). This work has produced inconsistent results, which in combination with the general lack of effects found in the present study suggests that there may be little need to tailor intervention efforts to demographic subgroups within the broader cohort of older people.

\section{Implications}

The results from this study highlight the importance of life satisfaction, self-esteem, and purpose in life as focus areas for interventions aimed at preventing and ameliorating depressive symptoms among older people. While self-esteem exhibits traitlike stability (52), and is thus better suited to individual therapeutic intervention, life satisfaction and purpose in life have the potential to be modifiable through population-level interventions. As such, interventions that focus on ways of enhancing life satisfaction and purpose in life are likely to hold most potential for scalable prevention and amelioration strategies. Previous research suggests that encouraging people to participate in meaningful tasks such as hobbies, leisure activities, and/or volunteering can increase their life satisfaction and purpose in life (53-56). These activities have been suggested to provide older adults with opportunities that promote purpose in life and life satisfaction from (i) the relationships formed, (ii) the pursuit of goals, (iii) maintenance of independence, and (iv) engagement with the community $(56,57)$. These types of activities have also been found to be associated with social 
support, self-efficacy, and self-rated health (58-60). Further, participation in meaningful tasks appears to be beneficial in helping individuals adjust to age-related losses such as retirement (i.e., loss of work role) and bereavement $(53,55,60)$. Encouraging older adults to engage in meaningful activities and facilitating relevant opportunities for them to do so may thus constitute means of preventing and ameliorating depressive symptoms in later life.

\section{Limitations, Future Directions, and Strengths}

The main limitation of the present study was its crosssectional design. Further research is needed to test the results longitudinally to assess whether the identified relationships hold over time. Another potential limitation was the use of convenience sampling, although the resulting sample was largely similar in profile to the population of older Australians, with the exception of living arrangement (see Table 1). Future studies should seek to access representative samples to test whether these results are generalizable. Similar research could also be conducted in other countries to assess the extent to which the identified relationships are relevant to other cultures. Given the inclusion of a broad range of psychological constructs in this study, a further potential limitation was the risk of social desirability bias in responses. To minimize this risk, an "armslength" data collection method was used in the form of selfadministered surveys. This approach has been found to result in more truthful responses to sensitive questions compared to when an interviewer is present (61).

The primary strength of this study was the large number of potential protective factors incorporated into a model that was tested on a substantial sample of community-dwelling older people. However, despite the wide range of factors included in this study, some potentially relevant variables were not assessed and could be incorporated into future research. In particular, including a measure of objective health could provide additional important data and overcome the limitations associated with relying solely on self-rated health as an indicator of physical wellbeing. Further, recent research suggests that sleep and diet quality may influence older people's experience of depressive symptoms (16), making these potentially important variables to include in future studies.

\section{CONCLUSION}

This study assessed the relative importance of a large number of factors that have been established in prior work as being protective against depressive symptoms in older adults. Life satisfaction and purpose in life were found to be the most influential factors, and could therefore be the focus of prevention

\section{REFERENCES}

1. World Health Organization. Depression. (2018). Available online at: https:// www.who.int/news-room/fact-sheets/detail/depression (accessed October, 2019).

2. United Nations Department of Economic and Social Affairs Population Division. World Population Prospects: The 2017 Revision, Key Findings and and amelioration strategies targeting depressive symptoms in later life. Previous research has shown that engaging in activities perceived to be meaningful can increase older adults' life satisfaction and purpose in life. As such, it is likely that programs that focus on enhancing these protective factors could decrease the risk of depressive symptoms and improve overall well-being among older adults.

\section{DATA AVAILABILITY STATEMENT}

The datasets presented in this article are not readily available because ethics clearance was received on the basis that information would be confidential. Requests to access the datasets should be directed to spettigrew@georgeinstitute.org.au.

\section{ETHICS STATEMENT}

The studies involving human participants were reviewed and approved by Curtin University Human Research Ethics Committee. The patients/participants provided their written informed consent to participate in this study.

\section{AUTHOR CONTRIBUTIONS}

CW conducted the analyses and took primary responsibility for preparing the manuscript. MJ, SP, and CW collected the data. SP and MJ assisted with manuscript preparation. All authors contributed to study conceptualization, read and edited drafts of the manuscript, and approved the final manuscript. All authors contributed to the article and approved the submitted version.

\section{FUNDING}

This work was supported by an Australian Research Council (Grant Number: DP140100365) and an Australian Government Research Training Program (RTP) Scholarship awarded to CW. The funders played no role in the conducting of the research or the reporting of the results.

\section{ACKNOWLEDGMENTS}

The authors wish to acknowledged Zenobia Talati and Nicole Biagioni for their assistance in data collection.

\section{SUPPLEMENTARY MATERIAL}

The Supplementary Material for this article can be found online at: https://www.frontiersin.org/articles/10.3389/fpubh. 2020.579304/full\#supplementary-material
Advance Tables. (2017). Available online at: https://esa.un.org/unpd/wpp/ Publications/Files/WPP2017_KeyFindings.pdf (accessed October, 2019).

3. World Health Organization. World Report on Ageing and Health. (2015). Available online at: http://www.who.int/ageing/events/world-report-2015launch/en/ (accessed October, 2019).

4. Thielke SM, Diehr P, Unützer J. Prevalence, incidence, and persistence of major depressive symptoms in the Cardiovascular Health Study. 
Aging Ment Health. (2010) 14:168-76. doi: 10.1080/136078609030 46537

5. Chapman DP, Perry GS. Peer reviewed: depression as a major component of public health for older adults. Prev Chronic Dis. (2008) 5:1-9.

6. Cheruvu VK, Chiyaka ET. Prevalence of depressive symptoms among older adults who reported medical cost as a barrier to seeking health care: findings from a nationally representative sample. BMC Geriatrics. (2019) 19:192. doi: 10.1186/s12877-019-1203-2

7. Chew-Graham C, KovandŽić M, Gask L, Burroughs H, Clarke P, Sanderson $\mathrm{H}$, et al. Why may older people with depression not present to primary care? Messages from secondary analysis of qualitative data. Health Soc Care Community. (2012) 20:52-60. doi: 10.1111/j.1365-2524.2011.01015.x

8. Rodda J, Walker Z, Carter J. Depression in older adults. BMJ. (2011) 343:6837. doi: $10.1136 / \mathrm{bmj} . \mathrm{d} 5219$

9. Bruine de Bruin W, Parker AM, Strough J. Age differences in reported social networks and well-being. Psychol Aging. (2019) 35:159-68. doi: $10.1037 /$ pag0000415

10. Fiske A, Wetherell JL, Gatz M. Depression in older adults. Annu Rev Clin Psychol. (2009) 5:363-89. doi: 10.1146/annurev.clinpsy.032408.153621

11. von Faber M, van der Geest G, van der Weele GM, Blom JW, van der Mast RC, Reis R, Gussekloo J. Older people coping with low mood: a qualitative study. Int Psychogeriatr. (2016) 28:603-12. doi: 10.1017/S1041610215002264

12. Allen J. Older People and Wellbeing. London: Institute for Public Policy Research (2008).

13. Cole MG, Dendukuri N. Risk factors for depression among elderly community subjects: a systematic review and meta-analysis. Am J Psychiatry. (2003) 160:1147-56. doi: 10.1176/appi.ajp.160.6.1147

14. Djernes JK. Prevalence and predictors of depression in populations of elderly: a review. Acta Psychiatrica Scandinavica. (2006) 113:372-87. doi: 10.1111/j.1600-0447.2006.00770.x

15. Vink D, Aartsen MJ, Schoevers RA. Risk factors for anxiety and depression in the elderly: a review. J Affect Disord. (2008) 106:29-44. doi: 10.1016/j.jad.2007.06.005

16. Worrall C, Jongenelis M, Pettigrew S. Modifiable protective and risk factors for depressive symptoms among older community-dwelling adults: a systematic review. J Affect Disord. (2020) 272:305-17. doi: $10.1016 /$ j.jad.2020.03.119

17. Aihara Y, Minai J, Aoyama A, Shimanouchi, S. Depressive symptoms and past lifestyle among Japanese elderly people. Community Ment Health J. (2011) 47:186-93. doi: 10.1007/s10597-010-9317-1

18. Chang YC, Lu MC, Hu IH, Wu WCI, Hu SC. Effects of different amounts of exercise on preventing depressive symptoms in community-dwelling older adults: a prospective cohort study in Taiwan. BMJ Open. (2017) 7:10. doi: 10.1136/bmjopen-2016-014256

19. Cho J, Jin Y, Kang H. Weight status, physical activity, and depression in Korean older adults. J Epidemiol. (2018) 28:292-9. doi: 10.2188/jea.JE20170083

20. Han HR, Kim M, Lee HB, Pistulka G, Kim KB. Correlates of depression in the Korean American elderly: focusing on personal resources of social support. $J$ Cross-cult Gerontol. (2007) 22:115-27. doi: 10.1007/s10823-006-9022-2

21. Ku PW, Steptoe A, Liao Y, Sun WJ, Chen LJ. Prospective relationship between objectively measured light physical activity and depressive symptoms in later life. Int J Geriatr Psychiatry. (2018) 33:58-65. doi: 10.1002/gps.4672

22. Lee H, Lee JA, Brar JS, Rush EB, Jolley CJ. Physical activity and depressive symptoms in older adults. Geriatr Nurs. (2014) 35:37-41. doi: 10.1016/j.gerinurse.2013.09.005

23. Park JE, Lee JY, Kim BS, Kim KW, Chae SH, Cho MJ. Abovemoderate physical activity reduces both incident and persistent late-life depression in rural Koreans. Int J Geriatr Psychiatry. (2015) 30:766-75. doi: $10.1002 / g p s .4244$

24. Strawbridge WJ, Deleger S, Roberts RE, Kaplan GA. Physical activity reduces the risk of subsequent depression for older adults. Am J Epidemiol. (2002) 156:328-34. doi: 10.1093/aje/kwf047

25. Sun F, Park NS, Roff LL, Klemmack DL, Parker M, Koenig HG, et al. Predicting the trajectories of depressive symptoms among southern community-dwelling older adults: the role of religiosity. Aging Ment Health. (2012) 16:189-98. doi: $10.1080 / 13607863.2011 .602959$
26. Yoo JS, Chang SJ, Kim HS. Prevalence and predictive factors of depression in community-dwelling older adults in South Korea. Res Theory Nurs Pract. (2016) 30:200-11. doi: 10.1891/1541-6577.30.3.200

27. Bisschop MI, Kriegsman DM, Beekman AT, Deeg DJ. Chronic diseases and depression: the modifying role of psychosocial resources. Soc Sci Med. (2004) 59:721-33. doi: 10.1016/j.socscimed.2003.11.038

28. Hedberg P, Gustafson Y, Alèx L, Brulin C. Depression in relation to purpose in life among a very old population: a five-year follow-up study. Aging Ment Health. (2010) 14:757-63. doi: 10.1080/13607861003713216

29. Horowitz A, Reinhardt JP, Kennedy GJ. Major and subthreshold depression among older adults seeking vision rehabilitation services. Am J Geriatr Psychiatry. (2005) 13:180-7. doi: 10.1097/00019442-200503000-00002

30. Lue BH, Chen LJ, Wu SC. Health, financial stresses, and life satisfaction affecting late-life depression among older adults: a nationwide, longitudinal survey in Taiwan. Arch Gerontol Geriatr. (2010) 1:34-8. doi: 10.1016/S0167-4943(10)70010-8

31. Orth U, Robins RW, Trzesniewski KH, Maes J, Schmitt M. Low self-esteem is a risk factor for depressive symptoms from young adulthood to old age. $J$ Abnorm Psychol. (2009) 118:472-8. doi: 10.1037/a0015922

32. Sowislo JF, Orth U. Does low self-esteem predict depression and anxiety? A meta-analysis of longitudinal studies. Psychol Bull. (2013) 139:213-40. doi: $10.1037 / \mathrm{a} 0028931$

33. Windsor TD, Curtis RG, Luszcz MA. Sense of purpose as a psychological resource for aging well. Dev Psychol. (2015) 51:975-86. doi: $10.1037 / \operatorname{dev} 0000023$

34. Wood AM, Joseph S. The absence of positive psychological (eudemonic) wellbeing as a risk factor for depression: a ten year cohort study. J Affect Disord. (2010) 122: 213-7. doi: 10.1016/j.jad.2009.06.032

35. Pettigrew S, Jongenelis M, Newton RU, Warburton J, Jackson B. Research protocol for a randomized controlled trial of the health effects of volunteering for seniors. Health Qual Life Outcomes. (2015) 13:1-8. doi: 10.1186/s12955-015-0263-z

36. Australian Bureau of Statistics (ABS). Census of Population and Housing: Reflecting Australia - Stories from the Census, 2016. Catalog no. 2071.0. (2019). Available online at: https://www.abs.gov.au/AUSSTATS/abs@.nsf/ Lookup/2071.0Main+Features100012016?OpenDocument (accessed October, 2019).

37. Radloff LS. The CES-D scale: a self-report depression scale for research in the general population. Appl Psychol Meas. (1977) 1:385-401. doi: $10.1177 / 014662167700100306$

38. Ryff CD. Happiness is everything, or is it? Explorations on the meaning of psychological well-being. J Personal Soc Psychol. (1989) 57:1069-81. doi: 10.1037/0022-3514.57.6.1069

39. Rosenberg M. Society and the Adolescent Self-Image. Princeton, NJ: Princeton University Press (1965). doi: 10.1515/9781400876136

40. Cutrona CE, Russell DW. The provisions of social relationships and adaptation to stress. Adv Personal Relation. (1987) 1:37-67.

41. Schwarzer R, Jerusalem M. Generalized self-efficacy scale. In: Weinman J, Wright S, Johnston M, editors. Measures in Health Psychology: A User's Portfolio. Windsor: NFER-NELSON (1995). p. 35-7.

42. Inglehart RC, Haerpfer C, Moreno A, Welzel C, Kizilova K, Diez-Medrano J, et al. World Values Survey: Round Six - Country-Pooled Datafile 2010-2014. Madrid: JD Systems Institute (2014).

43. The Department of Health. Australia's Physical Activity and Sedentary Behaviour Guidelines and the Australian 24-hour Movement Guidelines. (2019). Available online at: https://wwwl.health.gov.au/internet/main/ publishing.nsf/Content/health-pubhlth-strateg-phys-act-guidelines (accessed October, 2019).

44. Idler EL, Benyamini Y. Self-rated health and mortality: a review of twenty-seven community studies. J Health Soc Beh. (1997) 38:21-37. doi: $10.2307 / 2955359$

45. Hayes AF. Introduction to Mediation, Moderation, and Conditional Process Analysis: A Regression-Based Approach. New York, NY: Guilford Publications (2017).

46. Mammen G, Faulkner G. Physical activity and the prevention of depression: a systematic review of prospective studies. Am J Prev Med. (2013) 45:649-57. doi: 10.1016/j.amepre.2013.08.001 
47. Teychenne M, Ball K, Salmon J. Physical activity and likelihood of depression in adults: a review. Prev Med. (2008) 46:397-411. doi: 10.1016/j.ypmed.2008.01.009

48. Alexandrino-Silva C, Alves TF, Tófoli LF, Wang YP, Andrade LH. Psychiatry: life events and social support in late life depression. Clinics. (2011) 66:233-8. doi: 10.1590/S1807-59322011000200009

49. Gong F, Zhao D, Zhao Y, Lu S, Qian Z, Sun Y. The factors associated with geriatric depression in rural China: stratified by household structure. Psychol Health Med. (2018) 23:593-603. doi: 10.1080/13548506.2017.1400671

50. Isaac VM, Stewart R, Artero S, Ancelin, ML, Ritchie K. Social activity and improvement in depressive symptoms in older people: a prospective community cohort study. Am J Geriatr Psychiatry. (2009) 17:688-96. doi: 10.1097/JGP.0b013e3181a88441

51. Russell D, Taylor J. Living alone and depressive symptoms: the influence of gender, physical disability, and social support among hispanic and nonhispanic older adults. J Gerontol B Psychol Sci Soc Sci. (2009) 64:95-104. doi: 10.1093/geronb/gbn002

52. Orth U. The lifespan development of self-esteem. In: Specht J, editor. Personality Development Across the Lifespan. London: Elsevier Academic Press (2017). p. 181-95. doi: 10.1016/B978-0-12-804674-6.00012-0

53. Greenfield EA, Marks NF. Formal volunteering as a protective factor for older adults' psychological well-being. J Gerontol B Psychol Sci Soc Sci. (2004) 59:258-64. doi: 10.1093/geronb/59.5.S258

54. Irving J, Davis S, Collier A. Aging with purpose: systematic search and review of literature pertaining to older adults and purpose. Int J Aging Hum Dev. (2017) 85:403-37. doi: 10.1177/0091415017702908

55. Li Y. Recovering from spousal bereavement in later life: does volunteer participation play a role? J Gerontol B Psychol Sci Soc Sci. (2007) 62:257-66. doi: 10.1093/geronb/62.4.S257
56. Morrow-Howell N. Volunteering in later life: research frontiers. J Gerontol B Psychol Sci Soc Sci. (2010) 65:461-9. doi: 10.1093/geronb/gbq024

57. Boyle PA, Barnes LL, Buchman AS, Bennett DA. Purpose in life is associated with mortality among community-dwelling older persons. Psychosomatic Med. (2009) 71:574-9. doi: 10.1097/PSY.0b013e3181a5a7c0

58. Fiorillo D, Nappo N. Formal volunteering and self-perceived health. Causal evidence from the UK-SILC. Rev Soc Econ. (2017) 75:112-38. doi: 10.1080/00346764.2016.1186822

59. Musick MA, Wilson J. Volunteering and depression: the role of psychological and social resources in different age groups. Soc Sci Med. (2003) 56:259-69. doi: 10.1016/S0277-9536(02)00025-4

60. Van Willigen M. Differential benefits of volunteering across the life course. J Gerontol B Psychol Sci Soc Sci. (2000) 55:308-18. doi: 10.1093/geronb/55.5.S308

61. Krumpal I. Determinants of social desirability bias in sensitive surveys: a literature review. Qual Quant. (2013) 47:2025-47. doi: $10.1007 / \mathrm{s} 11135-011-9640-9$

Conflict of Interest: The authors declare that the research was conducted in the absence of any commercial or financial relationships that could be construed as a potential conflict of interest.

Copyright (c) 2020 Worrall, Jongenelis, McEvoy, Jackson, Newton and Pettigrew. This is an open-access article distributed under the terms of the Creative Commons Attribution License (CC BY). The use, distribution or reproduction in other forums is permitted, provided the original author(s) and the copyright owner(s) are credited and that the original publication in this journal is cited, in accordance with accepted academic practice. No use, distribution or reproduction is permitted which does not comply with these terms. 